Goldschmidt 2021 Abstract

https://doi.org/10.7185/gold2021.7777

\section{Global Mercury Observation Training Network (GMOS-Train)}

\author{
MILENA HORVAT ${ }^{1}$, JEROEN E SONKE ${ }^{2}$, LARS-ERIC \\ HEIMBUERGER-BOAVIDA ${ }^{3}$, ALEKSANDRA LOBNIK ${ }^{4}$, \\ SOFI JONSSON ${ }^{5}$, AURELIEN DOMMERGUE ${ }^{6}$, NICOLA \\ PIRRONE $^{7}$, DAVID AMOUROUX ${ }^{8}$, RALF EBINGHAUS $^{9}$, \\ JOËL KNOERY ${ }^{10}$, WARREN CORNS ${ }^{11}$, ALES LAPANJE ${ }^{1}$, \\ DAVID KOCMAN ${ }^{1}$, IAN M HEDGECOCK ${ }^{7}$, JOHANNES \\ BIESER $^{12}$, VOLKER MATTHIAS ${ }^{13}$, CORINNA SCHRUM ${ }^{14}$, \\ ANNE LORRAIN ${ }^{15}$ AND DAVID POINT ${ }^{16}$ \\ ${ }^{1}$ Jožef Stefan Institute \\ ${ }^{2}$ CNRS/Université de Toulouse \\ ${ }^{3}$ Institut Méditerranéen d'Océanologie - MIO, CNRS \\ ${ }^{4} \mathrm{IOS}$ \\ ${ }^{5}$ Stockholm University \\ ${ }^{6}$ Université Grenoble Alpes \\ ${ }^{7}$ CNR-IIA \\ ${ }^{8}$ CNRS, Université de Pau et Pays de l'Adour, E2S UPPA, \\ IPREM \\ ${ }^{9}$ Institute of Coastal Research, Helmholtz-Zentrum \\ ${ }^{10}$ IFREMER \\ ${ }^{11}$ PA Analytical \\ ${ }^{12}$ Helmholtz-Zentrum Hereon \\ ${ }^{13}$ Helmholtz-Zentrum Geesthacht \\ ${ }^{14}$ Helmholtz-Zentrum Geesthacht Centre for Materials and \\ Coastal Research \\ ${ }^{15}$ IRD \\ ${ }^{16}$ Géosciences Environnement Toulouse, CNRS/IRD/Université \\ Paul Sabatier Toulouse III \\ Presenting Author: milena.horvat@ijs.si
}

With the signing of the UNEP Minamata Convention in 2013 and its ratification in 2017, the world's governments have accepted that mercury $(\mathrm{Hg})$ is toxic and of global relevance; scientific needs will therefore shift towards best implementation practices of the Convention. The Convention requests that each Party shall implement activities to reduce emissions and releases of mercury to the environment and report on the measures taken and the effectiveness of these measures. Moreover, dealing with the research, development and monitoring calls for (i) improved modelling and geographically representative monitoring of levels of mercury and mercury compounds environmental compartments; (ii) assessments of the impact of mercury and mercury species on human health and the environment; (iii) harmonized methodologies; (iv) information on the environmental cycle, transport, transformation and fate of mercury and mercury compounds in a range of ecosystems, taking appropriate account of the distinction between anthropogenic and natural emissions and releases of mercury and of remobilization of mercury from historic deposition.

Despite decades of mercury science, we still lack answers to some of the most basic questions on fundamental mercury transformations and fluxes in the environment. The objectives of the MSCA ITN GMOS-TRAIN network are (1) to provide urgently needed training in mercury science within the context of the UNEP Minamata convention, and (2) to bridge key knowledge gaps on biogeochemical mercury cycling that currently hamper the optimization of national environmental policy regarding mercury emissions. The project addresses priority issues in relation to atmospheric and terrestrial mercury dynamics, and transformations processes of mercury and its uptake in lower food webs in the oceanic environment. On a horizontal level metrological concepts and principles will assure the comparability of measurement data. Empirical and modelling assessments of the exchange processes will also be conducted, and new knowledge integrated in the coupled model frameworks for policy scenarios.

The process of training a pool of 15 Early Stage Researchers ( $\mathrm{PhD}$ students) at experienced research groups inside and outside Europe represents an excellent capacity building needed for the implementation of the Minamata Convention. 